\title{
Effects of storage conditions on phytochemical and stability of purple corn cob extract powder
}

\author{
Chutikarn KAPCUM ${ }^{1}$, Juntanee URIYAPONGSON ${ }^{1 *}$
}

\begin{abstract}
Recently, purple corn cob has been gaining popularity for a dietary supplement and natural colorant. However, phytochemicals in waxy purple corn cob (WPC) are likely degraded during storage; thus, the microencapsulation by spray drying was used for lengthening those compounds. This work focused on the phenolic and anthocyanin content and antioxidant activity (AOA) in WPC extract microcapsules by hydroxypropyl beta-cyclodextrin $(\mathrm{HP} \beta \mathrm{CD})$ during storage at 4 and $30^{\circ} \mathrm{C}$ for 60 days. The results revealed that only peonodin-3-glucoside at $30^{\circ} \mathrm{C}$ was found as a higher decrease than $4{ }^{\circ} \mathrm{C}$. Pelagonidin-3-glucoside and AOA were found more stable at both storage temperatures; however, the increase of protocatechuic acid and hydroxybenzoic acid were observed during storage, especially at $30^{\circ} \mathrm{C}$. Consequently, the storage under $4{ }^{\circ} \mathrm{C}$ was appropriate to maintain the phytochemical content in WPC extract powder.
\end{abstract}

Keywords: waxy purple corn cob; microencapsulation; phenolics; anthocyanins; hydroxypropyl beta-cyclodextrin.

Practical Application: The microencapsulation of WPC extract by HP $\beta C D$ demonstrates the considerable potential to improve the stability of bioactive compounds during storage at cool and room temperature; thus, HP $\beta C D$ represents a competent alternative coating material with sensitive compounds from plant extract. Additionally, this work also provides the valuable information describing the phytochemical composition and concentration in the cob, which is perhaps used as a low-cost source of nutraceutical compound for the functional food and pharmaceutical industry.

\section{Introduction}

Corn (Zea mays L.) has been primarily consumed in South America with various colors such as white, yellow, red and purple. Purple corn, a special corn variety with high anthocyanin concentration in aleurone layer and cob (Zhang et al., 2010), is reported to possess antioxidant ability higher than the non-colored corn (Lopez-Martinez et al., 2011). In Thailand, the developed variety of waxy purple corn presents dark purple color due to the considerable the high amount of anthocyanins, phenolics and antioxidant activity, leading to the increased consumption of waxy purple corn as fresh foods (Harakotr et al., 2014); meanwhile, its cob tends to be largely neglected. Indeed, the cob of purple corn is reported to contain high amount of anthocyanins, including cyanidin-3-glucoside, pelagonidin-3glucoside and peonidin-3-glucoside (Yang et al., 2008); additionally, protocatechuic, hydroxybenzoic, vanillic, caffeic, $p$-coumaric and ferulic acid, the majority of phenolic compound, are also found in the cob (Harakotr et al., 2014), thereby becoming one of a most interesting source of nutraceutical food. Certain investigations of clinical study confirm that waxy purple corn cob (WPC) offers considerable benefits in various biological activities, e.g. preventing hyperlipidemia and cerebrovascular diseases (Zhang et al., 2010). Consequently, the development of value added products from WPC to be a potential source of nutraceutical is of great interest.
Nevertheless, most of phenolics and anthocyanins are sensitive and decomposed by environmental factors during storage, such as temperature, light and $\mathrm{pH}$ (Ersus \& Yurdagel, 2007). Anthocyanin molecule tends to change and transform into other degraded products during storage or heat processing (Rødtjer et al., 2010; Sivamaruthi et al., 2016). However, there is an effective technique able to enhance the stability of those compounds against storage conditions called microencapsulation. This technique mainly relies on spray drying, where the compounds are entrapped by coating material, thus protecting them from environment factors. Hydroxypropyl beta-cyclodextrins (HP $\beta C D)$ is a chemical modification of beta-cyclodextrins from esterification at the hydroxyl groups of the glucose residues. Hydroxypropyl substitutions help to improve solubility and their binding ability, resulting in increasing the stability of core compound (Khan et al., 1998). Nevertheless, recently little literature has focused on microencapsulation using $\mathrm{HP} \beta \mathrm{CD}$ as a coating material by spray drying of anthocyanin and phenolic compound in plant extract (Wilkowska et al., 2016). Due to those benefits, the addition of this novel coating agent encourages food industry to preserve the unstable compounds in WPC extract in this study. Significant retention of phytochemical compounds during storage is an ideal characteristic for microcapsules powder. However, there is limited information on the storage stability of phytochemical 
compounds in WPC extract microcapsules. Thus, the aims of this work was to evaluate the various anthocyanin and phenolic content, and AOA of WPC extract powder using $\mathrm{HP} \beta \mathrm{CD}$ as a carrier agent during storage at 4 and $30^{\circ} \mathrm{C}$ for 60 days.

\section{Materials and methods}

\subsection{Chemicals and reagents}

2,2'-azino-bis (3-ethylbenzothiazoline-6-solfonic acid diammonium salt (ABTS), vanillic acid, caffeic acid, and ferulic acid were purchased from Fluka (Steinheim, Germany). Hydroxybenzoic acid, gallic acid, quercetin hydrate, protocatechuic acid, $p$-coumaric acid, syringic acid, sinapic acid, rutin, peonidin-3-glucoside, pelaganidin-3-glucoside and 6-hydroxy-2,5,7,8-tetramethylchroman-2-carboxylic acid (Trolox) were purchased from Sigma-aldrich (St. Louis, MO, USA). Cyanidin-3-glucoside was purchased from Chromadex ${ }^{\circledR}$ (Irvine, CA, USA). HP $\beta C D$ was purchased from Zibo Qianhui Biological Technology Co., Ltd. (China).

\subsection{Material preparation}

WPC was obtained from the Plant Breeding Research Center for Sustainable Agriculture, Khon Kaen University, Thailand. After drying at $60^{\circ} \mathrm{C}$ (moisture content $<10 \%$ ) by hot air oven (model FD 240; Binder, Germany), the epidermis section was used and grounded into fine particle (60 mesh).

\subsection{WPC extract powder preparation}

$60 \mathrm{~g}$ of WPC was extracted in $750 \mathrm{~mL}$ of $30 \%$ ethanol by sonication bath (Crest Utrasonic, Tru-sweep, NJ, USA) at $60^{\circ} \mathrm{C}$ for $30 \mathrm{~min}$ and then stirred by magnetic stirring at $70^{\circ} \mathrm{C}$ for $15 \mathrm{~min}$. The extract was filtered through a fine-mesh nylon cloth (pore diameter $10 \mu \mathrm{m}$ ). Afterward, the residue was re-extracted in $450 \mathrm{~mL}$ solvent using the same extraction procedure as described above. The two extract fractions were pooled together and $\mathrm{HP} \beta \mathrm{CD}$ was then added to the extract in concentration of $20 \%(\mathrm{w} / \mathrm{w})$. The mixture was then homogenized using high pressure homogenizer (M-110P Microfluidizer ${ }^{\circledR}$, USA) at pressure 10,000 psi. The spray drying process was carried out in a laboratory-scale spray dryer (model B290; Buchi, Flawil, Switzerland), with liquid feed rate $0.6 \mathrm{~L} / \mathrm{h}$, spray air flow-rate of $0.5 \mathrm{~m}^{3} / \mathrm{h}$ and the aspirator flow-rate of drying air was fixed to $80 \%$. The inlet air temperature was operated at $140{ }^{\circ} \mathrm{C}$ with outlet temperature of $80 \pm 5^{\circ} \mathrm{C}$.

\subsection{Storage stability test of WPC extract powder}

Prior to storage at controlled temperatures at 4 and $30^{\circ} \mathrm{C}$, the microcapsules were transferred to aluminum foil bag and then sealed under the vacuum condition. The samples were analyzed for antioxidant activity throughout 60 days and individual phenolics and anthocyanins were measured by the ultra-performance liquid chromatography (UPLC).

\subsection{Extraction of WPC powder for chemical determinations}

$0.5 \mathrm{~g}$ of microcapsule was dissolved in $2 \mathrm{~mL}$ deionized water until fully dissolved, and then added by $18 \mathrm{~mL}$ methanol. After centrifugation at 3,000 rpm for $5 \mathrm{~min}$, the clear solution was filtered through a filter paper (Whatman No.1). The excess of methanol was removed by a rotary evaporator at $40^{\circ} \mathrm{C}$ under vacuum. The volume of the extracts was adjusted to $5 \mathrm{~mL}$ in a volumetric flask by the addition of methanol.

\subsection{Determination of phenolic acids by UPLC-DAD}

UPLC analyses were performed using the Waters ${ }^{\circledR}$ Acquity UPLC $^{\circledR}$ system equipped with diode array detector (DAD). The system was controlled; data was collected and analyzed using Empower 2 software. The extracts were passed through a $0.22 \mu \mathrm{m}$ filter before injection into the UPLC system. $2 \mu \mathrm{L}$ extract was loaded into the Acquity UPLC BEH C18 column $(2.1 \times 50 \mathrm{~mm}, 1.7 \mu \mathrm{m})$, the temperature was operated at $40^{\circ} \mathrm{C}$, at a flow rate of $0.5 \mathrm{~mL} / \mathrm{min}$ and the chromatograms were recorded at 280,320 and $370 \mathrm{~nm}$, respectively. In this study, mobile phases used were acetonitrile (A) and 1\% acetic acid (B). The solvent gradient was performed as follows: $0 \% \mathrm{~A}$ at $0 \mathrm{~min}$, increasing to $30 \% \mathrm{~A}$ within $15 \mathrm{~min}$, increasing to $80 \% \mathrm{~A}$ within $3 \mathrm{~min}$ and increasing to $100 \% \mathrm{~A}$ within the next $5 \mathrm{~min}$, and decreasing to $0 \%$ A within the next $2 \mathrm{~min}$, respectively, and equilibrated before the following injection. The individual phenolics were quantified according to their peak area against the previously determined standard calibration curves. The results were expressed as $\mathrm{mg}$ of each phenolic per kg based on dry basis (d.b.).

\subsection{Determination of anthocyanins by UPLC-DAD}

UPLC analysis was carried out using a Waters ${ }^{\circledR}$ Acquity UPLC ${ }^{\circledR}$ system (Waters Corporation, Milford, MA, USA.). $2 \mu \mathrm{L}$ filtered extract was loaded onto an Acquity UPLC BEH C18 column $(2.1 \times 50 \mathrm{~mm}, 1.7 \mu \mathrm{m})$. The mobile phase was a gradient solvent containing $0.3 \%$ phosphoric acid (A) and acetonitrile (B); elution conditions were as follows: $90 \% \mathrm{~A}$ at $0 \mathrm{~min}$, decreasing to $80 \%$ A within 2 min and increasing to $90 \%$ A within the next $0.1 \mathrm{~min}$, holding at $90 \% \mathrm{~A}$ for $0.9 \mathrm{~min}$ before equilibration at $90 \% \mathrm{~A}$, respectively. The solvent flow rate was set at $0.6 \mathrm{~mL} / \mathrm{min}$ and the column temperature at $40^{\circ} \mathrm{C}$. The wavelength detection was set at $525 \mathrm{~nm}$, and the results were expressed as $\mathrm{mg}$ of each anthocyanin per kg based on dry basis (d.b.).

\subsection{Determination of antioxidant activity (AOA)}

ABTS radical scavenging assay was assessed by measuring the reduction of $\mathrm{ABTS}^{*+}$ radical cations, as described by Stratil et al. (2006) with some modifications. The stock solution was prepared by mixing ABTS $(7 \mathrm{mM})$ with $\mathrm{K}_{2} \mathrm{O}_{8} \mathrm{~S}_{2}(4.95 \mathrm{mM})$ with the ratio $1: 1(\mathrm{v} / \mathrm{v})$ for $12 \mathrm{~h}$ at room temperature in the dark. The working solution was diluted with phosphate buffer saline (PBS, pH 7.4) to absorbance $1.0 \mathrm{AU}$ at $734 \mathrm{~nm}$ (Shimadzu UV-1800 spectrophotometer, Japan) prior to measurement. $40 \mu \mathrm{L}$ of the sample extract (with appropriate dilution) was reacted with $4.0 \mathrm{~mL}$ working solution for $10 \mathrm{~min}$. Antioxidant activity was expressed as mg Trolox equivalents per kg based on dry basis (mg Trolox/kg, d.b.).

\subsection{Statistical analysis}

The experiments were conducted in duplicate and the data were reported as means \pm standard deviations (SD). The experimental design was a split-plot with storage time as 
the whole-plot factor, and storage temperature as the subplot factor. The analysis of variance (ANOVA) was carried out by IBM $^{\circledR}$ SPSS Statistics version 19.0 (SPSS Inc., USA), meanwhile, Duncan's multiple range test (DMRT) was applied to determine the differences between means at $\mathrm{p} \leq 0.05$.

\section{Results and discussion}

\subsection{The differences of anthocyanin content in WPC extract powder during storage}

The concentration of anthocyanins in microcapsules at different storage time and temperatures is shown in Table 1 . The results show that cyanidin-3-glucoside is the major anthocyanin in WPC extract powder, followed by peonidin-3-glucoside and pelargonidin-3-glucoside, respectively. Similar trend was also observed in Chinese purple corn cob (Yang \& Zhai, 2010) and Thai WPC extract (Kapcum et al., 2016). Cyanidin-3-glucoside significantly decreased throughout storage time; however, storage temperature showed no significant effect on this compound. Pelargonidin-3-glucoside showed fairly stable for both storage temperatures and times, whereas peonidin-3-glucoside was affected by storage temperature at $30^{\circ} \mathrm{C}$. Regarding of the total content of anthocyanin, the value was calculated as a sum of contents of individual anthocyanins analyzed. The greater degradation of total content of anthocyanin was also found in storage temperature at $30{ }^{\circ} \mathrm{C}$ along with storage time. The anthocyanin degradation caused by storage temperature was also observed in roselle calyces extract spray dried powder in which the highest loss was found at $37^{\circ} \mathrm{C}$, followed by $25^{\circ} \mathrm{C}$ and $4{ }^{\circ} \mathrm{C}$, respectively (Idham et al., 2012). Therefore, storage temperature is considered an important factor affecting anthocyanin stability.

\subsection{The differences of phenolic content in WPC extract powder during storage}

This work, three hydroxybenzoic acids (protocatechuic acid, hydroxybenzoic acid and vanillic acid), four hydroxycinamic acids ( $p$-coumaric aicd, caffeic acid, ferulic acid, and sinapic acid) and two flavonols (rutin and quercetin) were detected in microcapsules (Table 2). According to our previous study, syringic acid was found to be the major phenolic compound in WPC when detected using HPLC with single wavelength detector (280 nm) (Kapcum et al., 2016). Meanwhile, rutin was the most abundant compound in WPC extract powder, followed by syringic acid, protocatechuic and sinapic acid, respectively, when determined by UPLC with multiple wavelength detectors (280, 320 and $370 \mathrm{~nm})$. According to the theoretical explanation, the optimum detection wavelengths for phenolics exhibit the differences due to their different characteristic absorbance groups (Zhang et al., 2013). Therefore, the great precision of flavonol compounds was achieved by wavelength detection at $370 \mathrm{~nm}$. The concentration of some phenolics varied significantly $(\mathrm{p} \leq 0.05)$ according to different storage temperatures and time. Protocatechuic acid significantly increased for both storage temperatures and storage time, while the increase of hydroxybenzoic acid was observed at $30^{\circ} \mathrm{C}$. These results are believed that the formation of certain compounds of hydroxybenzoic acid group during storage involves anthocyanin degradation products. The generation of protocatechuic and hydroxybenzoic acid descends from the B-ring of the anthocyanidin aglycon from cyaniding-3-glucoside and pelagonidin-3-glucoside, respectively (Sun et al., 2011). These observations are supported by Rødtjer et al. (2010), suggesting that the formation of some phenolic acids during the storage, especially hydroxybenzoic acid and protocatechuic acid, is caused by anthocyanidin degradation. Syringic acid was the only compound found a decrease after 60 days of storage at both temperatures, whereas sinapic acid slightly decreased at $30^{\circ} \mathrm{C}$ ( $\left.\mathrm{p} \leq 0.05\right)$. Moreover, vanillic acid, $p$-coumaric acid, caffeic acid, ferulic acid and sinapic acid showed a subtle change during storage ( $p>0.05$ ). According to Laine et al. (2008), various phenolic acids in encapsulated powder of cloudberry extract by maltodextrins were found to increase during storage at $25^{\circ} \mathrm{C}$ for 64 days; however, some compounds were observed to be sensitive to storage particularly flavonol compounds, likely due to oxidation reaction. Interestingly, flavonol group (rutin and quercetin) in WPC powder seems to be more stable during storage, which may because that the flavonol compounds are protected by complexation of flavonol molecule in the hydrophobic cavity

Table 1. Differences of anthocyanins ${ }^{\mathrm{a}}$ in waxy purple corn cob extract powder during different storage conditions.

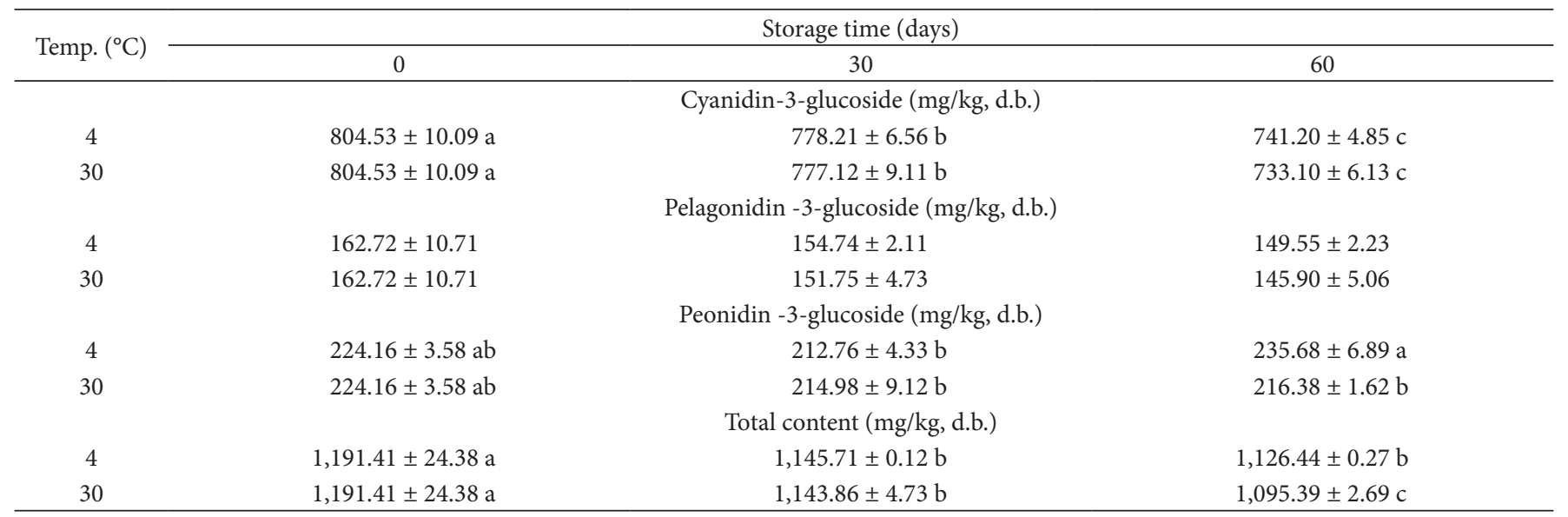

a: The data are expressed as the means \pm SD of duplicate samples; Mean values in the same column and row, for each type of compound, with different letters are significantly different $(\mathrm{p} \leq 0.05)$; The results were expressed as $\mathrm{mg}$ of each types of anthocyanin per kg based on dry basis (d.b.). 
Table 2. Differences of phenolics ${ }^{\mathrm{a}}$ and antioxidant activity ${ }^{\mathrm{a}}$ in waxy purple corn cob extract powder during different storage conditions.

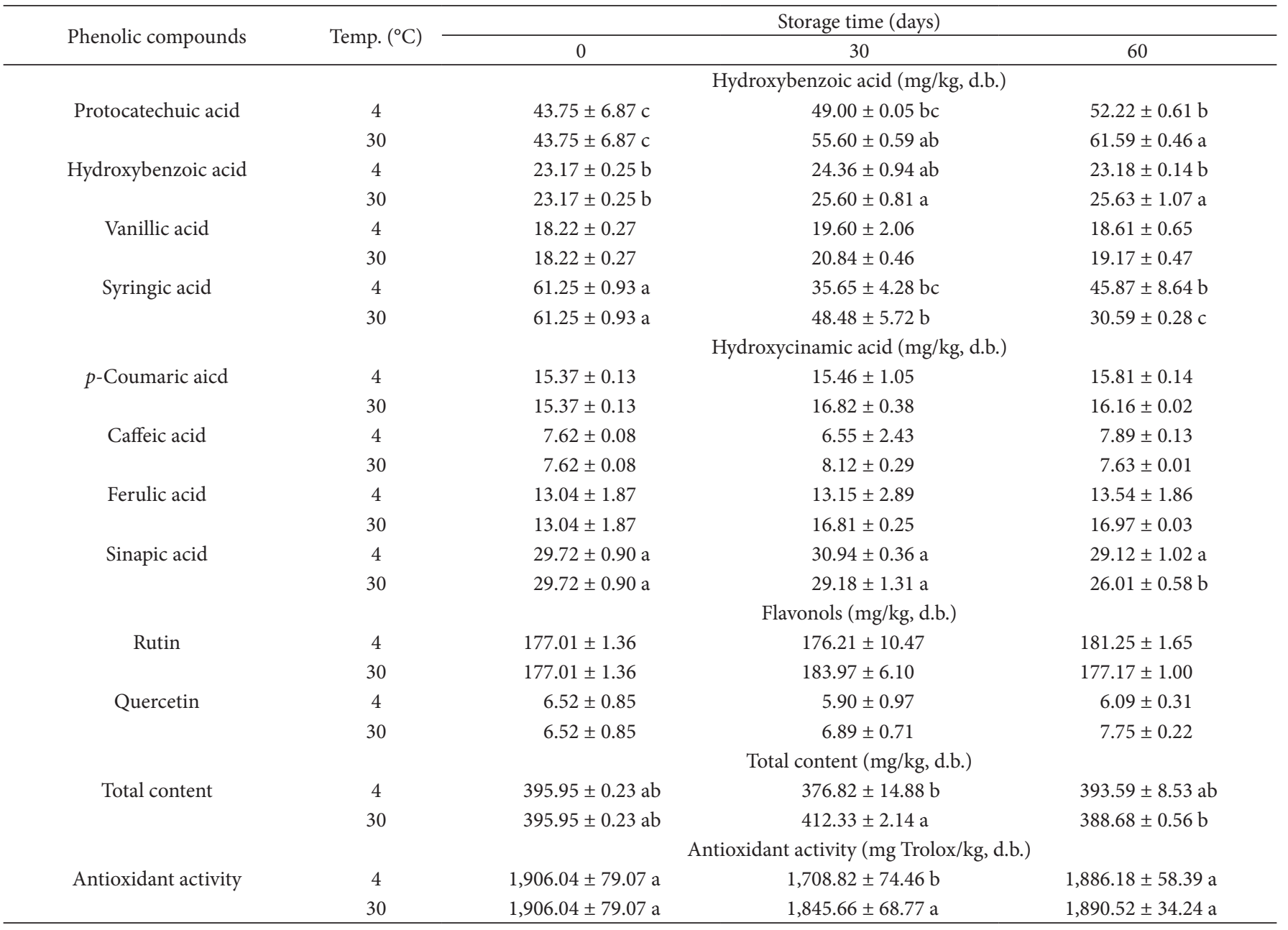

a: The data are expressed as the means \pm SD of duplicate samples; Mean values in the same column and row, for each type of compound, with different letters are significantly different ( $\mathrm{p} \leq$ 0.05); The results were expressed as $\mathrm{mg}$ of each types of compound per kg based on dry basis (d.b.).

of cyclodextrin (Lucas-Abellán et al., 2008). Regarding the total phenolic content (calculated as a sum of contents of individual phenolics analyzed), there was no significant difference in powder during storage for 60 days $(p>0.05)$. Similar observation reported by Galmarini et al. (2013), the phenolic compounds showed no significant changes during 70 days of storage, either at 28 or $38^{\circ} \mathrm{C}$.

\subsection{The AOA in WPC extract powder during storage}

AOA in the microcapsules is presented in Table 2. The AOA remained unchanged during storage for 60 days at both temperatures. In this study, the total content of phenolic compounds and AOA remained stable during storage; meanwhile, the total content of anthocyanin decreased, indicating that phenolics were the main contributor to AOA. Similar result was obtained by Tonon et al. (2009), working spray-dried açai powder, finding that total phenolic content and AOA remained unchanged during storage at $40^{\circ} \mathrm{C}$ for 15 days. The increase of some phenolics, especially hydroxybenzoic group, from the formation of anthocyanins degradation products, was observed in this study, likely due to $\mathrm{AOA}$ and maintenance in AOA in product (Sivamaruthi et al.,
2016). In addition, it is likely that phenolics with low-molecular were generated to be oligomeric and polymeric compounds; consequently, the number of reactive sites increases and AOA improves, resulting in equal or improved AOA during the storage (Laine et al., 2008; Bakowska-Barczak \& Kolodziejczyk, 2011). In our case, the stability of AOA in the samples during storage implied that WPC extract powder can be used as a functional food supplement.

\section{Conclusions}

This study has shown that WPC extract powder encapsulated by $\mathrm{HP} \beta C D$ could achieve high stability in various types of phenolic compounds and AOA throughout 60 days of storage at both cool $\left(4^{\circ} \mathrm{C}\right)$ and room temperature $\left(30^{\circ} \mathrm{C}\right)$. Moreover, protocatechuic acid and hydroxybenzoic acid increased during storage at $30{ }^{\circ} \mathrm{C}$; meanwhile, the anthocyanin compounds decreased. It is argued from this study that HP $\beta C D$ could be a good carrier agent for encapsulation of WPC extract powder as a function of preservation and shelf life extension in terms of functional property for health. 


\section{Acknowledgements}

The research project was financially supported by Higher Education Research Promotion and National Research University Project of Thailand, Office of the Higher Education Commission, through the Food and Functional Food Research Cluster of Khon Kaen University, Thailand.

\section{References}

Bakowska-Barczak, A. M., \& Kolodziejczyk, P. P. (2011). Black currant polyphenols: Their storage stability and microencapsulation. Industrial Crops and Products, 34(2), 1301-1309. http://dx.doi.org/10.1016/j. indcrop.2010.10.002.

Ersus, S., \& Yurdagel, U. (2007). Microencapsulation of anthocyanin pigments of black carrot (Daucuscarota L.) by spray drier. Journal of Food Engineering, 80(3), 805-812. http://dx.doi.org/10.1016/j. jfoodeng.2006.07.009.

Galmarini, M. V., Maury, C., Mehinagic, E., Sanchez, V., Baeza, R. I., Mignot, S., Zamora, M. C., \& Chirife, J. (2013). Stability of individual phenolic compounds and antioxidant activity during storage of a red wine powder. Food and Bioprocess Technology, 6(12), 3585-3595. http://dx.doi.org/10.1007/s11947-012-1035-y.

Harakotr, B., Suriharn, B., Tangwongchai, R., Scott, M. P., \& Lertrat, K. (2014). Anthocyanins and antioxidant activity in coloured waxy corn at different maturation stages. Journal of Functional Foods, 9, 109-118. http://dx.doi.org/10.1016/j.jff.2014.04.012.

Idham, Z., Muhamad, I. I., \& Sarmidi, M. R. (2012). Degradation kinetics and colors stability of spray-dried encapsulated anthocyanins from Hibiscus Sabdariffa L. Journal of Food Process Engineering, 35(4), 522-542. http://dx.doi.org/10.1111/j.1745-4530.2010.00605.x.

Kapcum, N., Uriyapongson, J., Alli, I., \& Phimphilai, S. (2016). Anthocyanins, phenolic compounds and antioxidant activities in colored corn cob and colored rice bran. International Food Research Journal, 23(6), 2347-2356.

Khan, A. R., Forgo, P., Stine, K. J., \& D'Souza, V. T. (1998). Methods for selective modifications of cyclodextrins. Chemical Reviews, 98(5), 1977-1996. PMid:11848955. http://dx.doi.org/10.1021/cr970012b.

Laine, P., Kylli, P., Heinonen, M., \& Jouppila, K. (2008). Storage stability of microencapsulated cloudberry (Rubus chamaemorus) phenolics. Journal of Agricultural and Food Chemistry, 56(23), 11251-11261. PMid:18989975. http://dx.doi.org/10.1021/jf801868h.

Lopez-Martinez, L. X., Parkin, K. L., \& Garcia, H. S. (2011). Phase II-inducing, polyphenols content and antioxidant capacity of corn (Zea mays L.) from phenotypes of white, blue, red and purple colors processed into masa and tortillas. Plant Foods for Human Nutrition, 66(1), 41-47. PMid:21327968. http://dx.doi.org/10.1007/ s11130-011-0210-Z.

Lucas-Abellán, C., Fortea, I., Gabaldón, J. A., \& Núñez-Delicado, E. (2008). Encapsulation of quercetin and myricetin in cyclodextrins at acidic pH. Journal of Agricultural and Food Chemistry, 56(1), 255-259. PMid:18069793. http://dx.doi.org/10.1021/jf0720640.

Rødtjer, A., Skibsted, L. H., \& Andersen, M. L. (2010). The role of phenolic compounds during formation of turbidity in an aromatic bitter. Food Chemistry, 123(4), 1035-1039. http://dx.doi.org/10.1016/j. foodchem.2010.05.056.

Sivamaruthi, B. S., Pengkumsri, N., Saelee, M., Kesika, P., Sirilun, S., Peerajan, S., \& Chaiyasut, C. (2016). Impact of physical treatments on stability and radical scavenging capacity of anthocyanidins. International Journal of Pharmacy and Pharmaceutical Sciences, 8(1), 162-167.

Stratil, P., Klejdus, B., \& Kuban, V. (2006). Determination of total content of phenolic compounds and their antioxidant activity in vegetables evaluation of spectrophotometric methods. Journal of Agricultural and Food Chemistry, 54(3), 607-616. PMid:16448157. http://dx.doi.org/10.1021/jf052334j.

Sun, J., Bai, W., Zhang, Y., Liao, X., \& Hu, X. (2011). Identification of degradation pathways and products of cyanidin-3-sophoroside exposed to pulsed electric field. Food Chemistry, 126(3), 1203-1210. http://dx.doi.org/10.1016/j.foodchem.2010.12.002.

Tonon, R. V., Brabet, C., Pallet, D., Brat, P., \& Hubinger, M. D. (2009). Physicochemical and morphological characterisation of açai (Euterpe oleraceae Mart.) powder produced with different carrier agents. International Journal of Food Science \& Technology, 44(10), 1950-1958. http://dx.doi.org/10.1111/j.1365-2621.2009.02012.x.

Wilkowska, A., Ambroziak, W., Czyżowska, A., \& Adamiec, J. (2016). Effect of microencapsulation by spray-drying and freeze-drying technique on the antioxidant properties of blueberry (Vaccinium myrtillus) juice polyphenolic compounds. Polish Journal of Food and Nutrition Sciences, 66(1), 11-16. http://dx.doi.org/10.1515/ pjfns-2015-0015.

Yang, Z., \& Zhai, W. (2010). Identification and antioxidant activity of anthocyanins extracted from the seed and cob of purple corn (Zea mays L.). Innovative Food Science \& Emerging Technologies, 11(1), 169-176. http://dx.doi.org/10.1016/j.ifset.2009.08.012.

Yang, Z., Han, Y., Gu, Z., Fan, G., \& Chen, Z. (2008). Thermal degradation kinetics of aqueous anthocyanins and visual color of purple corn (Zea mays L.) cob. Innovative Food Science \& Emerging Technologies, 9(3), 341-347. http://dx.doi.org/10.1016/j.ifset.2007.09.001.

Zhang, A., Wan, L., Wu, C., Fang, Y., Han, G., Li, H., Zhang, Z., \& Wang, H. (2013). Simultaneous determination of 14 phenolic compounds in grape canes by HPLC-DAD-UV using wavelength switching detection. Molecules, 18(11), 14241-14257. PMid:24252994. http:// dx.doi.org/10.3390/molecules181114241.

Zhang, Z., Yang, L., Ye, H., Du, X. F., Gao, Z. M., \& Zhang, Z. L. (2010). Effects of pigment extract from black glutinous corncob in a high-fat-fed mouse model of hyperlipidemia. European Food Research and Technology, 230(6), 943-946. http://dx.doi.org/10.1007/ s00217-010-1242-6. 